\title{
Payment methods may influence behaviour of primary care dentists
}

\author{
Abstracted from \\ Brocklehurst P, Price J, Glenny AM, Tickle M, Birch S, Mertz E, Grytten J. \\ The effect of different methods of remuneration on the behaviour of primary care dentists. \\ Cochrane Database Syst Rev. 2013; 11: Art. No. CD009853. DOI: 10.1002/14651858.CD009853.pub2. \\ Address for correspondence Luisa Fernandez Mauleffinch, Review Group Co-ordinator, \\ Cochrane Oral Health Group, School of Dentistry, The University of Manchester, \\ Coupland III Building, Oxford Road, Manchester, M13 9PLUK. E-mail: luisa.fernandez@manchester.ac.uk
}

\section{Question: How does the way primary care dentists are paid impact on dental care delivered and outcomes for patients?}

Data sources The Cochrane Effective Practice and Organisation of Care (EPOC) Group Specialised Register; the Cochrane Central Register of Controlled Trials (CENTRAL), Medline, Embase, EconLit the NHS Economic Evaluation Database (EED) and the Health Economic Evaluations Database (HEED).

Study selection Randomised controlled trials (RCTs), non-randomised controlled clinical trials (NRCTs), controlled before-after (CBA) studies and interrupted time series (ITS) studies were considered. Study selection was undertaken independently by three reviewers. Feefor-service payments, fixed salary payments, capitation payments of combinations thereof included.

Data extraction and synthesis Standard Cochrane methodological procedures were followed.

Results Two cluster-RCTs, with data from 503 dental practices, representing 821 dentists and 4771 patients, met the selection criteria. The risk of bias for the two studies was considered to be high and the overall quality of evidence for the outcomes was low/very low for all outcomes, as assessed using the GRADE approach.

One study conducted in the four most deprived areas of Scotland used a factorial design to investigate the impact of fee-for-service and an educational intervention on the placement of fissure sealants. The authors reported a statistically significant increase in clinical activity in the arm that was incentivised with a fee-for-service payment. Measures of health service utilisation or patient outcomes were not reported. The second study used a parallel group design undertaken over a three-year period to compare the impact of capitation payments with fee-for-service payments on primary care dentists' clinical activity. The study reported on measures of clinical activity, patient outcomes and healthcare costs. Teeth were restored at a later stage in the disease process in the capitation system and the clinicians tended to see their patients less frequently and tended to carry out fewer fillings and extractions, but also tended to give more preventive advice.

There was insufficient information regarding the cost-effectiveness of

This paper is based on a Cochrane Review published in the Cochrane Library 2013, issue 11 (see www.thecochranelibrary.com for information). Cochrane Reviews are regularly updated as new evidence emerges and in response to feedback, and the Cochrane Library should be consulted for the most recent version of the review. the different remuneration methods.

Conclusions Financial incentives within remuneration systems may produce changes to clinical activity undertaken by primary care dentists. However, the number of included studies is limited and the quality of the evidence from the two included studies was low/very low for all outcomes. Further experimental research in this area is highly recommended given the potential impact of financial incentives on clinical activity, and particular attention should be paid to the impact this has on patient outcomes.

\section{Commentary}

The method of remuneration of primary care dentists which delivers the highest quality dental care and outcomes for patients is an extremely important and relevant question - both in terms of concerns about the increasingly stretched NHS budget and also the potential role remuneration can have on patients' oral health and on improving quality of dental services across all the quality domains: person-centred, safe, effective, efficient, equitable, and timely. ${ }^{1}$ In the UK, The Review Body on Doctors and Dentists Remuneration 42nd Report 2014 stated that payment has a crucial role in recruitment, retention and motivation of doctors and dentists, but that the priority of payment in the NHS is clear - it 'should place patients at the heart of all it does' ${ }^{2}$

Currently, General Dental Practitioners in England and Wales are contracted to provide a set number of UDAs (units of dental activity), whereas in Scotland and Northern Ireland, GDPs are remunerated with a blended payment encompassing fee-per-service, capitation and continuing care payments. However, reform of dental primary care contracts is on the agenda, for example: in England new NHS dental contracts have been piloted, ${ }^{3}$ and in Scotland children's prevention has been introduced to the Statement of Dental Remuneration via the Childsmile programme. ${ }^{4}$ It is essential to inform these changes with the best evidence on improving dental service quality and patients' oral health.

A systematic review has been carried out in this area by the Cochrane Effective Practice and Organisation of Care Group, aiming to determine the impact of different remuneration mechanisms on the behaviour and practice of primary care dentists and on patients' outcomes. ${ }^{5}$

An extensive global literature search was undertaken, identifying 5,595 potential studies. These were narrowed down using strict inclusion and exclusion criteria and resulted in the only two 
Table 1 Comparison of fee-per-service vs capitation payments systems

\begin{tabular}{l|l}
\hline Fee-per-service & Capitation \\
\hline increased clinical activity (fillings and extractions) & fewer fillings and extractions \\
\hline earlier restoration of caries & caries restoration at a later stage \\
\hline more frequent appointments & less frequent appointments \\
\hline less preventive advice given to patients & more preventive advice given to patients \\
\hline dentists more likely to introduce innovations into their dental practice & $\begin{array}{l}\text { a greater number of children were referred to the public dental service from } \\
\text { dentists receiving capitation }\end{array}$ \\
\hline dentists felt more tempted to over-prescribe treatment & dentists felt more tempted to under-prescribe treatment
\end{tabular}

relevant randomised controlled trials identified: Coventry et al. $1989^{4}$ and Clarkson et al. 2008. ${ }^{5}$ In total, these studies contained data from 503 dental practices in the UK, representing 821 dentists and 4,771 patients. Both studies were assessed to have an overall high risk of bias and assessed as low/very low quality evidence by GRADE (Grading of Recommendations Assessment, Development and Evaluation) system. The authors had planned to undertake metaanalysis; however, due to the heterogeneity and small number of studies included, a qualitative narrative synthesis was performed.

The Coventry et al. 1989 randomised control trial took place over three years, comparing capitation and fee-per-service remuneration systems and the differences in activity that occurred in dentists treating children in general practice. ${ }^{6}$ A number of trends were identified within each of these remuneration schemes (Table 1).

The Clarkson et al. 2008 randomised control trial took place over 18 months and investigated if changes in remuneration, and also education, influenced dentists' placement of fissure sealants on second permanent molars on patients aged 12-14 years old. Dentists were separated into four arms: i) fee-per-sealant; ii) education on the evidence behind fissure sealing teeth; iii) both fee-per-service and education; iv) capitation payments only (the control arm). They discovered that there was a significant increase (9.8\%) in the number of sealants placed within the fee-per-service arm and that the fee-only intervention was the most cost-effective method of increasing sealant placement. ${ }^{7}$

The obvious disappointment with this systematic review was the lack of included/available randomised control trials. Additionally, the included studies focused only on the treatment of children, excluding the larger adult patient base of most GDPs. There is a great need for further and more robust research in this area. Cochrane Reviews by definition only include randomised control trials; however, research in the area of remuneration or complex policies is extremely difficult to research via a randomised control approach, given the nature of policy development and political imperative to reform. The Cochrane Review listed a number of studies which were excluded because they were not RCTs, but nevertheless would be highly informative to dentist remuneration policy. It would be interesting to see a review of these excluded studies and other grey (policy) literature taking a systematic search/quality appraisal and narrative synthesis approach to the review.

Promisingly, this Cochrane Review has highlighted the complex and varied repercussions that changes to a remuneration system can have on both dentists' behaviour and patients' outcomes. Strategically and evidence-based remuneration policies may have the potential to incentivise dentists to carry out treatment based on best-evidence and patients' needs.

Ailsa Malone ${ }^{a}$ and David I Conway a Glasgow Dental Hospital, NHS Greater Glasgow \& Clyde, b University of Glasgow Dental School, Glasgow, UK

1. Institute of Medicine Committee on Quality of Health Care in America: Crossing the Quality Chasm: A New Health System for the 21st Century. Washington DC, National Academy Press, 2001.

2. Review Body on Doctors' and Dentists' Remuneration 42nd report: 2014. Department of Health and Office of Manpower Economics. 13 March 2014. https:// www.gov.uk/government/uploads/system/uploads/attachment_data/file/288697/ Doctors_Dentists_42nd_report.pdf [Accessed March 2015]

3. Department of Health. NHS dental contract pilots - Learning after first two years of piloting. February 2014. https://www.gov.uk/government/uploads/system/uploads/ attachment_data/file/282760/Dental_contract_pilots_evidence_and_learning_ report.pdf [Accessed March 2015].

4. NHS Health Scotland. Childsmile incorporation into the statement booklet. http:// www.child-smile.org.uk/documents/5475.aspx [Accessed March 2015].

5. Brocklehurst P, Price I, Glenny AM, Tickle M, Birch S, Mertz E, Grytten I. The effect of different methods of remuneration on the behaviour of primary care dentists. Cochrane Database Syst Rev 2013; 11: CD009853

6. Coventry P, Holloway PJ, Lennon MA, Mellor A, Worthington HV. A trial of a capitation system of payment for the treatment of children in the General Dental Service. Final report. Dental Health Services Research Unit, University of Manchester. September, 1989. Community Dent Health 1989; 6: 1-63.

7. Clarkson JE, Turner S, Grimshaw JM, et al. Changing clinicians' behavior: a randomized controlled trial of fees and education. J Dent Res 2008; 87: 640-644.

Evidence-Based Dentistry (2015) 16, 4-5. doi:10.1038/sj.ebd.6401071 